\title{
COMORBIDITY OF EPILEPSY AND MENTAL DISORDERS
}

\author{
K. Naydenov ${ }^{1}$, Y. Petkov ${ }^{1}$, Iv. Manchev ${ }^{1}$, V. Chengeliyska ${ }^{2}$, D. Komsiyska ${ }^{1 *}$ \\ ${ }^{1}$ Department of Neurology and Psychiatry, Trakia University, Medical Faculty, Stara Zagora, Bulgaria \\ ${ }^{2}$ Center of Psychiatry Health, Plovdiv, Bulgaria
}

\begin{abstract}
PURPOSE The purpose of this manuscript is to present the comorbidity between epilepsy and mental disorders. Epilepsy is a widespread, socially significant disease that has been the subject of medical literature and practice since ancient times.

METHODS We have used a contingent of 100 epileptics, which were treated at the Neurological Clinic of the University of Medicine and Pharmacy "Prof. Dr. Stoyan Kirkovich" in Stara Zagora. RESULTS We found that in percentage ratio, out of the epileptic patients eighteen had mental illness. Out of these eighteen, depressive patients were $27.8 \%$, which fell within the range indicated in the world literature.

CONCLUSIONS As a conclusion, we suggest that the clinical assessment of the quality of life in epilepsy provides some opportunities for its improvement and should take its place in the bio-psychosocial approach to the disease.
\end{abstract}

Key words: Accompanying disorders, depression, anxiety, and alcoholism.

\section{INTRODUCTION}

Epilepsy is a widespread, socially significant disease that has been the subject of medical literature and practice since ancient times. The brain origin of epileptic seizures and the resulting clinical manifestations of epilepsy, in their diversity, make it an object of interdisciplinary professional interest. Studies have shown that patients with epilepsy are more prone to depression, especially those with temporal epilepsy. The analogy between psychotic patients and epileptics shows similar levels of discrimination in both cases, and it is difficult to determine which of these diseases has a higher rejection rate from society (1-3). Conditions such as schizophrenic-like psychoses and interstitial dysphoric disorder occur only in epilepsy. Their adequate recognition and treatment is of great importance for coping with the disease, improving the quality of life and preventing suicide attempts.

\footnotetext{
*Correspondence to: Detelina Yordanova Komsiyska, Department of Neurology and Psychiatry, Medical Faculty, Trakia University, Stara Zagora, Bulgaria, e-mail:

detelinakomsiiska@abv.bg, tel.: +359898277673/ 042648877
}

Psychiatric disorders are often associated with epilepsy. Studies show that up to $50 \%$ of patients with epilepsy develop psychic disorders, the most common being depression, anxiety and psychoses (4-5). This data suggests a two-way connection between the two diseases. It has been reported that postictal depression occurs more often in the presence of forehead focuses (6). The psychotic symptoms of postictal psychosis include illusions, hallucinations, and disorder of thought or mania that are usually transient, but can last up to a few weeks (7). Nearly $40 \%$ of patients with epilepsy have depression and therefore it is the most common psychiatric disease observed in epilepsy (8). The frequency of interictal psychosis is $4-10 \%$ (911). Depression is more often associated with epileptic focus in the dominant hemisphere $(12,13)$. Some antiepileptic drugs (AED) also can cause psychiatric disorders such as depression, anxiety, behavioral or cognitive problems and psychoses.

Epidemiological studies have shown that psychiatric disorders are more prevalent among people with epilepsy than in the general population (14-17). 
Table 1. Spread of psychiatric disorders in people suffering from epilepsy and in the general population

\begin{tabular}{|l|l|l|}
\hline & Patients with epilepsy & Total population \\
\hline Depression & $10-60 \%$ & $12-15 \%$ \\
\hline Anxiety & $19-45 \%$ & $2.5-6.5 \%$ \\
\hline Psychosis & $2-8 \%$ & $0.5-0.7 \%$ \\
\hline Attention deficit & $25-30 \%$ & $2-10 \%$ \\
\hline
\end{tabular}

\section{METHODS}

A total of 100 epileptics were studied for a period of one year, treated at the Neurological Clinic of the University of Medicine and Pharmacy "Prof. Dr. Stoyan Kirkovich" in Stara Zagora.

Table 2. Epileptic patients with mental disorders

\begin{tabular}{|l|l|}
\hline Affective disorders & 5 \\
\hline Organic personality disorder & 4 \\
\hline Anxiety disorder & 2 \\
\hline Dissociative disorder & 2 \\
\hline Schizophrenia & 2 \\
\hline Alcoholism & 2 \\
\hline Mental retardation & 1 \\
\hline
\end{tabular}

In percentage ratio, out of the patients with mental illness (18), depressive patients were $27.8 \%$, which fell within the range indicated in the world literature. They also have the highest relative share among all patients, as described by other authors. After that are organic personality disorders which are not considered in most studies. Patients with anxiety disorder are $11.1 \%$ and are aligned with psychoses and alcohol dependencies. The group of patients also had one with mental retardation, which is $5.5 \%$.

The results are similar to a study of 170 Thai epileptic patients, according to which the prevalence of mental disorders among epileptic patients is higher than in the general population. According to the study, 43 patients (25.3\%) had psychiatric illnesses. Out of them, $17.1 \%$ are depressed, $8.2 \%$ have a psychotic disorder, $7.1 \%$ with bipolar disorder, $8.2 \%$ with anxiety disorder, $2.9 \%$ with obsessive compulsive disorder (18). A recent study of 770 patients showed that depression and suicidal ideation were common in patients with epilepsy (19). According to a Hong Kong epilepsy study, there is a partial general genetic etiology between schizophrenia and epilepsy, confirming the model for common environmental factors, which may explain their comorbidity (20). Comparing the comorbidity between mental illnesses and epilepsy in prisoners compared to the general population,

\section{RESULTS}

Out of them there are a total of 18 psychiatric disorders distributed as follows: it is clear that personality disorders, psychoactive substance abuse and bipolar disorder predominate in prisoners, while depression and anxiety have the same frequency as in the general population (21). Cognitive-behavioral therapy is recommended as a first-line psychological approach and pharmacological treatment to cope with accompanying diseases, namely anxiety and depression (22).

Several studies suggest that primary depression and antidepressants increase the risk of developing epilepsy twice and suicidality by three to four times $(23,24)$. Mood disorders before the onset of epilepsy are associated with an increased risk of developing resistant epilepsy (24-26). From these observations, treatment of psychiatric accompanying illnesses should be followed by a better outcome of seizures and better tolerability of antiepileptic drugs. However, there is still insufficient data to establish whether such a dependency exists. Existing studies have shown that depressive disorder is the most common psychopathological comorbidity in epilepsy and is more common as accompanying disease than other chronic diseases. On average, the incidence rates range from $10-20 \%$ in patients with controlled epileptic seizures and up to $60 \%$ in patients with treatment-resistant seizures and can be diagnosed at any time during the course of the 
disease. Depressive disorders, through a relatively long-lasting affect, determine the way a person perceives reality. Influencing to one degree or another on overall functioning, they affect the course of the underlying disease, even more so in comorbidity with a central nervous system disease when pathogenetic processes occur within the same substrate.

Despite the high incidence, depressive disorders in epilepsy for the most part remain unrecognized and untreated. Significance for this, on the one hand, has their heterogeneity and a typicalness and, on the other hand, a number of psychosocial and cultural factors. The existence of common pathogenic mechanisms acting on both epilepsy and mood disorders is suggested as an explanation of their two-way relationship $(27,28)$. We believe that it is difficult to distinguish the mechanism by which the clinical factors characterizing epilepsy affect the onset of depressive disorder - directly through common pathogenetic mechanisms or indirectly, causing a psychopathological response according to the severity of the underlying disease. We assume that, in most cases, these mechanisms intertwine each other, and their distinction is the basis of a number of classification discussions. Psychosocial factors are essential in the etiology of depressive disorder in epilepsy. Adapting to epilepsy, negative assessment, and discrimination with which society "distinguishes the patient", the stressful effect of "getting an epileptic attack" are factors which epileptic patients need to deal with in their everyday lives. The need to cope daily with the psychosocial consequences of epilepsy and the high level of stress they generate is a significant risk factor for the occurrence of depressive experiences as a reaction to the presence of the disease. The sense of lack of control not only over the seizures, but over life as a whole, usually unlocks the psychological mechanisms of generating anxiety and depression. Anxiety and depression are the consequences of interaction between the patient and how he manages his life. Medication treatment could be another important etiological factor in depressive disorders in epilepsy. A number of antiepileptic drugs, with their effect on central nervous system mediator function, may potentiate the onset of depressive disorders $(29,30)$.

\section{CONCLUSION}

Comorbid psychiatric symptoms are common in patients with epilepsy. This accompanying emotional behavioral distress is associated with significantly worse quality of life and suggests that studies should pay more attention to the potential impact of accompanying mental disorders. The clinical assessment of the quality of life in epilepsy provides some opportunities for its improvement and should take its place in the bio-psycho-social approach to the disease.

\section{REFERENCES}

1. Beran, R. and Jennings, V., Doctor's perspectives of epilepsy. Epilepsia, 22:397, 1981.

2. Ribeiro, M., A doença psiquiátrica e a morte social. Arq Catar Med, 17:49, 1988.

3. Trevisol-Bittencourt, P. and Sander, J., Poor compliance em epilepsia: algumas considerações. J Liga Brasil Epilep, (no prelo), 1989.

4. Marsh, L. and Rao, V., Psychiatric complications in patients with epilepsy: a review. Epilepsy Res, 49:11-33, 2002.

5. Kanner, A., Depression in epilepsy: a frequently neglected multifaceted disorder. Epilepsy \& Behavior, 4:11-19, 2005.

6. Kanner, A. and Nieto, J., Depressive disorders in epilepsy. Neurology, 53:26-32, 1999.

7. Logsdail, S. and Toone, B., Postictal psychoses: a clinical and phenomenological description. Br J Psych, 152:246-252, 1988.

8. Robertson, M., Trimble, M. and Townsend, H., Phenomenology of depression in epilepsy. Epilepsia, 28:364-368, 1987.

9. Onuma, T., Adachi, N., Ishida, S., Katou, M. and Uesugi, S., Prevalence and annual incidence of psychosis in patients with epilepsy. Psychiatry Clin Neurosci, 49(3):267-268, 1995.

10.Sachdev, P., Schizophrenia-like psychosis and epilepsy: the status of the association [review]. Am J Psychiatry, 155:325-336, 1998.

11.Kanemoto, K., Tsuji, T. and Kawasaki, J., Reexamination of interictal psychoses based on DSM IV psychosis classification and international epilepsy classification. Epilepsia, 42:98-103, 2001.

12.Flor-Henry, P., Psychosis and temporal lobe epilepsy. A controlled investigation. Epilepsia, 10:363-395, 1969.

13.Sherwin, I., Psychosis associated with epilepsy: significance of the laterality of the epileptogenic lesion. J Neurol Neurosurg 
Psychiatry, 44:83-85, 1981.

14.Gaitatzis, A., Trimble, M. and Sander, J., The psychiatric comorbidity of epilepsy. Acta Neurologica Scandinavica, 110:207220, 2004.

15.Barragan, E. and Hernandez, J., ADHD and epilepsy, EEG and comorbidity. Epilepsia, 46:421, 2005.

16.Davies, S., Heyman, I. and Goodman, R., A population survey of mental health problems in children with epilepsy. Developmental Medicine and Child Neurology, 45:292- 295, 2003.

17.Devisnky, O., Psychiatric comorbidity in patients with epilepsy: implications for diagnosis and treatment. Epilepsy \& Behavior, 4:2-10, 2003.

18.Kuladee, S., Prachason, T., Srisopit, P., Trakulchang, D., Boongird, A., Wisajan, P. and Jullagate, S., Prevalence of psychiatric disorders in Thai patients with epilepsy. Epilepsy Behav., 90:20-24, 2018.

19.Friedman, D., Spruill, T., Liu, H., Tatsuoka, C., Stoll, S., Jobst, B., Fraser, R., Johnson, E., Chaytor, N. and Sajatovic, M., Depressive symptoms and suicidality among individuals with epilepsy enrolled in self-management studies: Results from the US Centers for Disease Control and Prevention Managing Epilepsy Well (MEW) Network. Epilepsy Behav., 87:235240, 2018.

20.Kwan, P. and Cherny, S., Genetic overlap between epilepsy and schizophrenia: Evidence from cross phenotype analysis in Hong Kong Chinese population. Am J Med Genet B Neuropsychiatr Genet, 177(1):8692, 2018.

21.Altınöz, A., Tosun Meriç, O., Tosun Altınöz, Ş., Eşsizoğlu, A. and Coşar, B., Psychiatric disorders comorbid with epilepsy in a prison sample. Seizure, 40:133-135, 2016.

22.Gasparini, S., Beghi, E., Ferlazzo, E., Beghi, M., Belcastro, V., Biermann, K., Bottini, G., Capovilla, G., Cervellione, R., Cianci, V., Coppola, G., Cornaggia, C., De Fazio, P., De Masi, S., De Sarro, G., Elia,
NAYDENOV K., et al.

M., Erba, G., Fusco, L., Gambardella, A., Gentile, V., Giallonardo, A., Guerrini, R., Ingravallo, F., Iudice, A., Labate, A., Lucenteforte, E., Magaudda, A., Mumoli, L., Papagno, C., Pesce, G., Pucci, E., Ricci, P., Romeo, A., Quintas, R., Sueri, C., Vitaliti, G., Zoia, R. and Aguglia, U., Management of psychogenic non-epileptic seizures: a multidisciplinary approach. Eur J Neurol, 26(2):205-215, 2019.

23.Hesdorffer, D., Ishihara, L. and Mynepalli, L., Epilepsy, suicidality, and psychiatric disorders: a bidirectional association. Ann Neurol, 72:184-191, 2012.

24.Jossephson, C., Lowerison, M. and Vallerand, I., Association of depression and treated depression with epilepsy and seizure outcomes: a Multicohort Analysis. JAMA Neurol, 74:533-539, 2017.

25.Hitiris, N., Mohanraj, R. and Norrie, J., Predictors of pharmacoresistant epilepsy. Epilepsy Res, 75:192-196, 2007.

26.Petrovski, S., Szoeke, C. and Jones, N., Neuropsychiatric symptomatology predicts seizure recurrence in newly treated patients. Neurology, 75:1015-1021, 2010.

27.Kanner, A., Can neurobiologic pathogenic mechanisms of depression facilitate the development of seizure disorders? Lancet Neurol, 11:1093-1102, 2012.

28.Kanner, A., Mazarati, A. and Koepp, M., Biomarkers of epileptogenesis: psychiatric comorbidities. Neurotherapeutics, 11:358372, 2014.

29.Mihaylova B., Petkova I., Rankova-Yotova Ch., Dimitrova G., Tanev I., Ivanova S., Tsakova A., Svinarov D. Plasma endothelin-1 and endothelin-A receptor concentrations in patients with primary open-angle glaucoma. Biotechnol \& Biotechnolog Eq, 2017; 31(4):782-787. ISSN: 1314-3530 (Online)

30.Dakov N., Kostova St., Tanev Iv. Selective laser trabeculoplasty in primary open angle glaucoma - efficiency and correlated parameters. Compt rend Acad bulg Sci 2018; 71(2):288-298. ISSN 2367-5535 